Eva Schumann (Hrsg.)

Hierarchie, Kooperation und Integration im Europäischen Rechtsraum 


\section{Abhandlungen der Akademie der Wissenschaften zu Göttingen}

Neue Folge

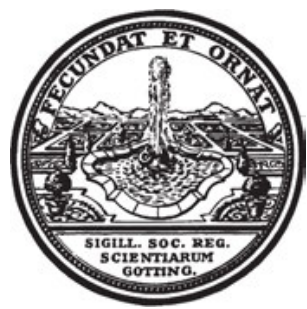

Band 38 


\section{Hierarchie, Kooperation und Integration im Europäischen Rechtsraum}

17. Symposion der Kommission

„Die Funktion des Gesetzes

in Geschichte und Gegenwart“

Herausgegeben von

Eva Schumann 


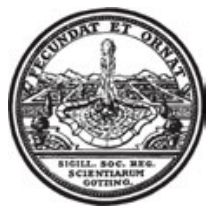

Vorgestellt von Eva Schumann durch Rundschreiben vom 19. November 2014.

ISBN 978-3-11-041000-6

e-ISBN (PDF) 978-3-11-041655-8

e-ISBN (EPUB) 978-3-11-041665-7

ISSN 0930-4304

\section{Library of Congress Cataloging-in-Publication Data}

A CIP catalog record for this book has been applied for at the Library of Congress.

Bibliografische Information der Deutschen Nationalbibliothek

Die Deutsche Nationalbibliothek verzeichnet diese Publikation in der

Deutschen Nationalbibliografie; detaillierte bibliografische Daten

sind im Internet über http://dnb.dnb.de abrufbar.

(c) 2015 Walter de Gruyter GmbH, Berlin/Boston

Satz: Michael Peschke, Berlin

Druck und Bindung: Hubert \& Co. GmbH \& Co. KG, Göttingen

๑) Gedruckt auf säurefreiem Papier

Printed in Germany

www.degruyter.com 